\title{
Management improvement through total cost reduction activi ty in a small and medium cosmetic manufacturing company: A case study
}

\author{
Jae-Sung Ji , Department of Smart Production and Management Engineering, Hanbat National \\ University,125 Dongseodaero, Yuseong-gu, Daejeon 34158, Korea. \\ Jae-Yong Lee, Department of Smart Production and Management Engineering, Hanbat National \\ University,125 Dongseodaero, Yuseong-gu, Daejeon 34158, Korea. \\ Soo-Yong Park, Department of Smart Production and Management Engineering, Hanbat National \\ University,125 Dongseodaero, Yuseong-gu, Daejeon 34158, Korea. \\ *Dong-Hyung Lee, Department of Smart Production and Management Engineering, Hanbat National \\ University,125 Dongseodaero, Yuseong-gu, Daejeon 34158, Korea, leedh@hanbat.ac.kr \\ ${ }^{*}$ Corresponding author.
}

\begin{abstract}
In order for companies to continue to grow and develop in a rapidly changing global economy and domestic working environment, the most fundamental concern is to improve management efficiency through enterprise-wide cost reduction. However, there are no case studies of enterprise-wide cost reduction activities of cosmetic manufacturers. Therefore, this study aims to analyze the company-wide cost reduction activities performed by a case company, an OEM/ODM cosmetic manufacturer, for about 3 years. The TCR activities of an example company can be largely divided into the introduction of a strategic target cost management system and post-cost reduction activities. In other words, a strategic preliminary target cost management system was introduced to calculate the target cost, and to reach the target cost. And then the company-wide improvement activities were promoted to reduce costs in the fields of raw and subsidiary materials, product profit and loss, and labor expenses. For 3 years, a thorough case study was conducted across the entire TCR activities conducted by Company C. In other words, the introduction, activities, evaluation, and follow-up management of TCR were investigated and reviewed for each stage of implementation, and the results of TCR were analyzed. As a result of the study, it was found that C's TCR activity greatly improved the company's operating profit. It was found that C's TCR activity greatly improved the company's operating profit. As of 2019, the company achieved a cost reduction of $23 \%$, including $7 \%$ for products, $24 \%$ for raw and subsidiary materials, $28 \%$ for labor expenses, and $15 \%$ for new. Also, the operating profit contribution rate increased significantly to $37 \%$ in $2017,35 \%$ in 2018 , and $50 \%$ in 2019 (3 years average of 41\%) The results of this study are expected to become a good benchmark for the introduction and activation of cost reduction systems not only for domestic and foreign industries but also for other industries
\end{abstract}

Keywords: Total Cost Reduction (TCR), Management Innovation, Target Cost Management, Cosme tics Manufacturing, Small and Medium Company.

$\begin{array}{lll}\text { Received: 08.12.2020 } & \text { Accepted: 10.01.2021 } & \text { Published: 02.02.2021 }\end{array}$

\section{INTRODUCTION}

In the meantime, many companies have promoted TQM (Total Quality Management) or Single PPM (Part Per Million) to strengthen their corporate competitiveness, and have got the good results [1-10]. However, in the case of SMEs, securing a cost advantage in the market is a shortcut to securing a competitive advantage, and cost reduction efforts are the most fundamental management innovation activity for a company's sustainable survival.

In spite of that, it is hard to find systematic and company-wide cost reduction activities that can be easily introduced and applied in industrial sites. In particular, there are no examples of company-wide cost reduction activities of cosmetics companies. In this regard, the case study on company-wide cost reduction activities conducted by OEM/ODM cosmetic manufacturers for about 3 years in a situation where the global economy is currently stagnating due to Corona 19 and negative economic growth is expected is very timely and meaningful. 


\section{Literature review}

\subsection{Target Costing}

Target Costing is a prior cost management method created by Toyota, Japan in 1965, with the concept of DTC (design to cost) and VE (value engineering) mindset to achieve the US Department of Defense's cost goal. In the fierce competitive environment for decades after the first oil crisis in 1973, it was rapidly introduced in Japan to survive from the automobile manufacturing industry to industries such as electrical equipment, machinery, and precision equipment [11].

The main process of target costing is shown in Figure 1. First, it recognizes the characteristics of the product and customer needs, and determines the target selling price and target cost. Second, allocate costs and perform segmentation work. Third, the target cost activity is carried out in earnest afterwards, and when the activity is completed, the feedback work is performed.

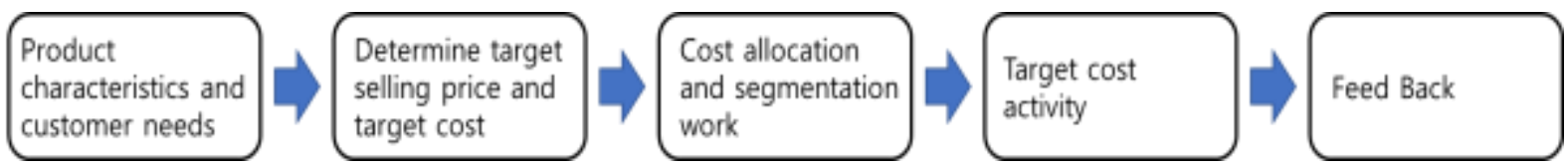

Figure 1 Target cost management process

\subsection{TCR (Total Cost Reduction) Activities}

TCR activities are targeted to all sectors/sectors related to the company's profit and loss to achieve the company's profit and loss goals. In other words, it is an organizational and continuous cost reduction activity in which all members participate. Kim [12] developed a P-VE (plant-value engineering) model suitable for the production process of the steel machinery industry and proposed it as a systematic and scientific cost innovation methodology. The P-VE model is a 5-step process and consists of Pre-Study $\rightarrow$ Target Costing $\rightarrow$ Redundancy Analysis $\rightarrow$ Idea Maximizing $\rightarrow$ Control.

\section{Status and Problems of an Example Company}

The example company is a small and medium-sized business that manufactures cosmetics specializing in OEM/ODM, and is strengthening its corporate competitiveness through the vision of Global Best OGM Company and management philosophy of transparent management, creative management, and knowledge management. Every year, about $5 \%$ of sales are invested in R\&D, and about 1,000 kinds of cosmetics are manufactured and produced by incorporating BB cream into beauty for the first time. As a result of emphasizing and implementing continuous change and innovation, it was awarded the Minister of Trade, Industry and Energy Award at the Enterprise Innovation Awards, 20 Million Dollar Export Tower on Trade Day, and was selected as a World Class 300 Company. The company has 518 full-time employees (as of 2019) in Korea, and sales in 2019 reached 347 billion won based on consolidated financial statements (Korea, China, and the United States).

However, the operating profit margin was decreased by $30.8 \%$ because of the increase in labor costs due to the increase in the minimum wage, and demand for a cut in processing costs due to excessive OEM supply. As a result of the analysis of these situation, the following four problems were drawn. First, efforts are being made to reduce costs, but the organization and operation system of enterprise-wide cost reduction activities are insufficient. Second, verification of the company's expenses (raw materials, subsidiary materials, cost etc.) usage history is not properly performed. Third, there is no standard for calculating the estimated unit price by company and type. Fourth, there is a difference in the standard for calculating the estimate price for each sales person. In order to solve these problems, the company decided to establish and operate company-wide cost reduction process (Total Cost Activity).

\section{Total Cost Reduction Activity}

\subsection{Design of TCR Flow charts}

In order to promote company-wide cost reduction activities according to the derived improvement measures, a TCR Flow Chart was designed, consisting of target cost calculation management activities and cost reduction, as shown in Figure 2. Its main contents are as follows.

First, target costs including selling prices and target profits are set according to mid- to long-term 
management plan activities, and the set target costs are allocated by parts for each function using the functional system diagram.

Second, after calculating the estimated cost to derive the difference between the estimated cost and the target cost, we establish and implement a TCR activity system that achieves the target cost by using VE, $\mathrm{CE}$, and guest engineering across the company.

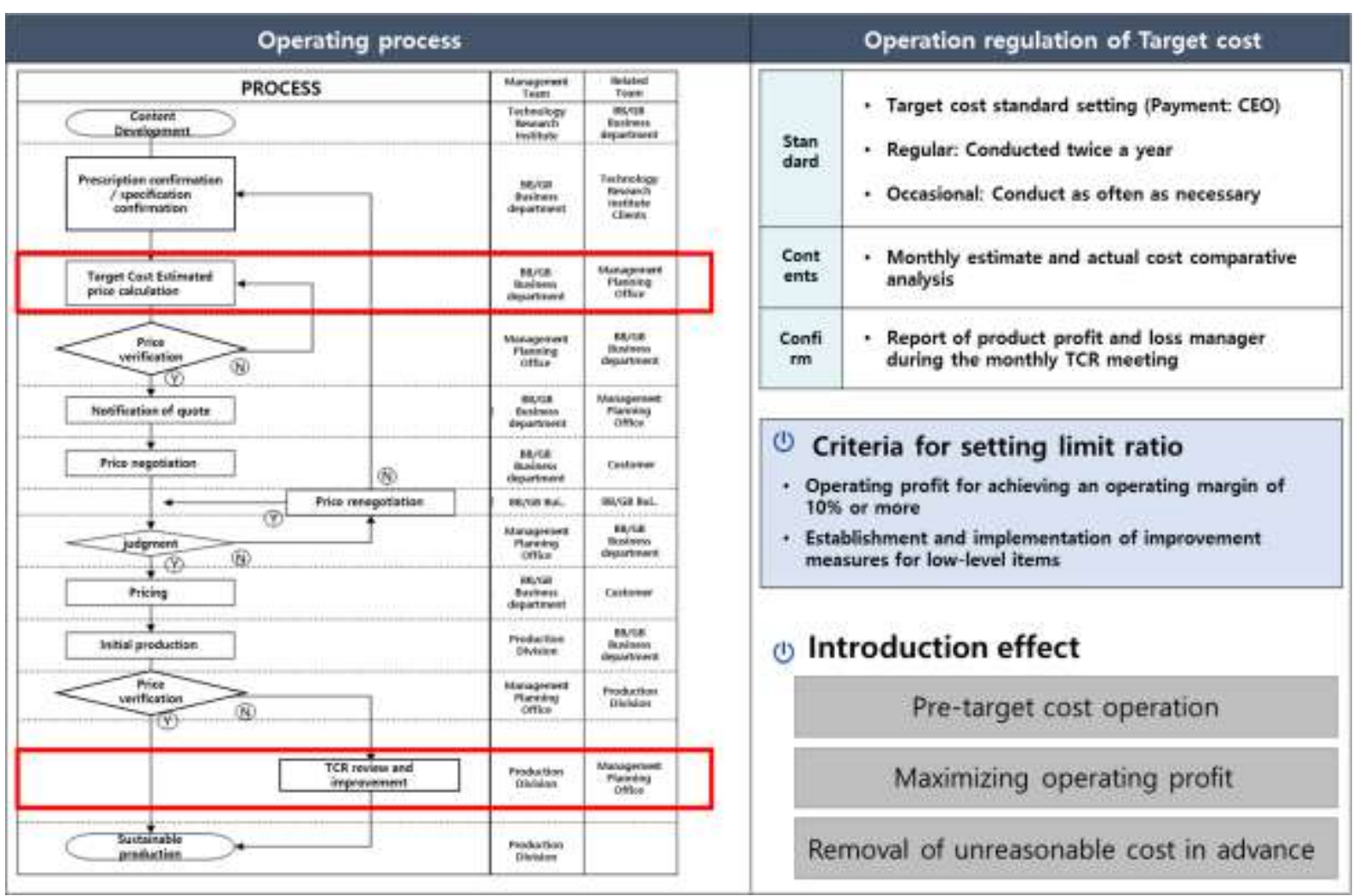

Figure 2 TCR flow chart and target cost operation regulations

\subsection{Construction of TCR operational organization}

TCR activities were promoted as follows by forming an operating organization as shown in Figure 3.

First, a plan for promoting TCR improvement activities is established across all sectors, and improvement progress checks and collaboration details are shared through TFT meetings 2-3 times a month. Second, in order to confirm the results of the TCR improvement by sector, regular (monthly, quarterly, semiannual, and annual) performance reporting meetings against the KPI indicator targets of all business sectors are held company-wide.

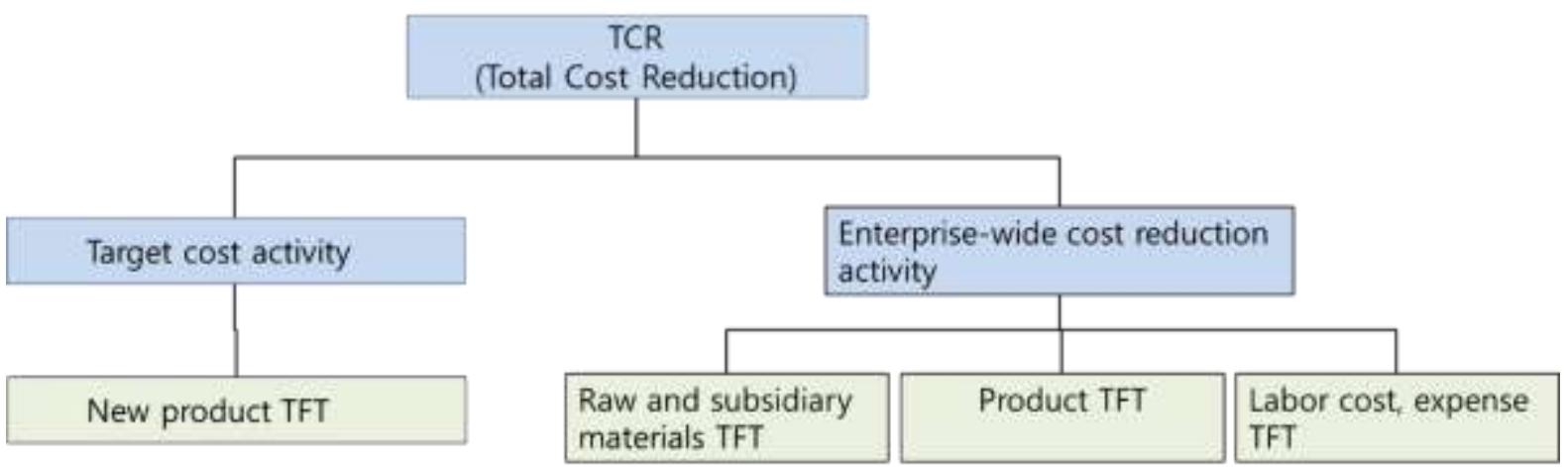

Figure 3 TCR operating organization and activities

\subsection{Steps of C company's TCR activities}

As shown in Figure 4 and Table 1, TCR activities consist of introduction stage $\rightarrow$ activity stage $\rightarrow$ 
evaluation stage $\rightarrow$ post management stage. A more detailed description of these TCR activities is as follows.

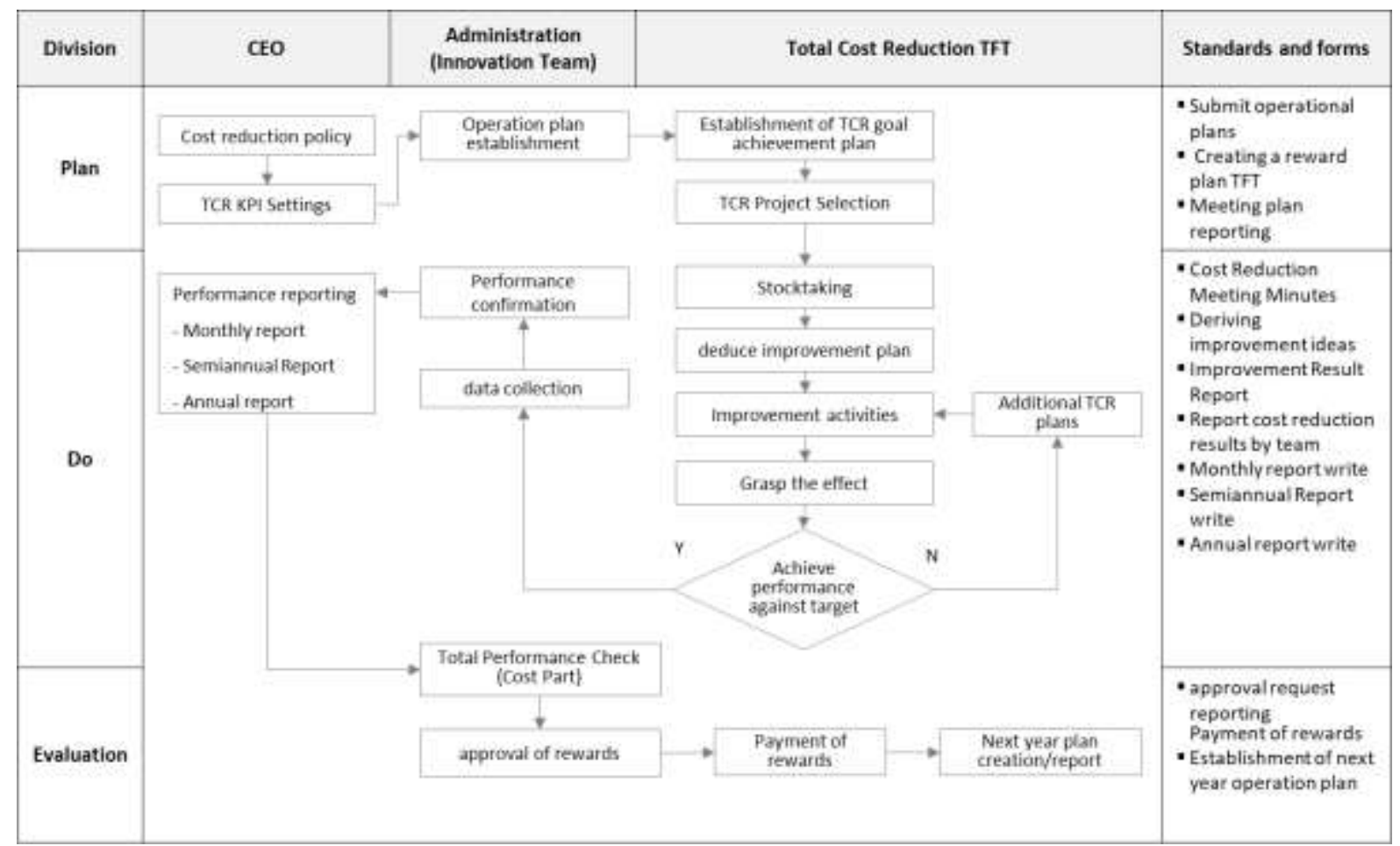

Figure 4 C Company's TCR Activity Process

Table1 Step-by-step TCR Activities

\begin{tabular}{|c|c|c|c|}
\hline No. & Stage & TCR Activitie & Management \\
\hline 1 & Introduction & $\begin{array}{l}\text { TCR manual writing and training } \\
\text { Target Costing Review and Confirmation } \\
\text { Target costing output criteria standardization }\end{array}$ & $\begin{array}{l}\text { Cost part } \\
\text { Each division }\end{array}$ \\
\hline
\end{tabular}

\section{Organization and operation of TCR}

TCR goal setting

$2 \quad$ Activity

TCR activities (Target Costing, enterprise cost Each division reduction)

KPI setting operation by business division

Annual, semi-annual, monthly performance reporting meeting against Total cost reduction targets

3 Evaluation Report performance against all business divisions' KPI indicator targets (quarterly,

Each division Each TFT semiannually, annually) Evaluation and award by TFT

4

Follow-Up Additional TCR workshops when performance is Management not achieved

Each division Innovation team

\subsubsection{Introduction Stage}

In the introduction stage, the necessity of cost reduction is communicated to all members, a TCR activity manual is prepared to educate members, and target costs are reviewed and confirmed, and target costing calculation standards are standardized. Figure 5 shows the process of achieving the target cost. 


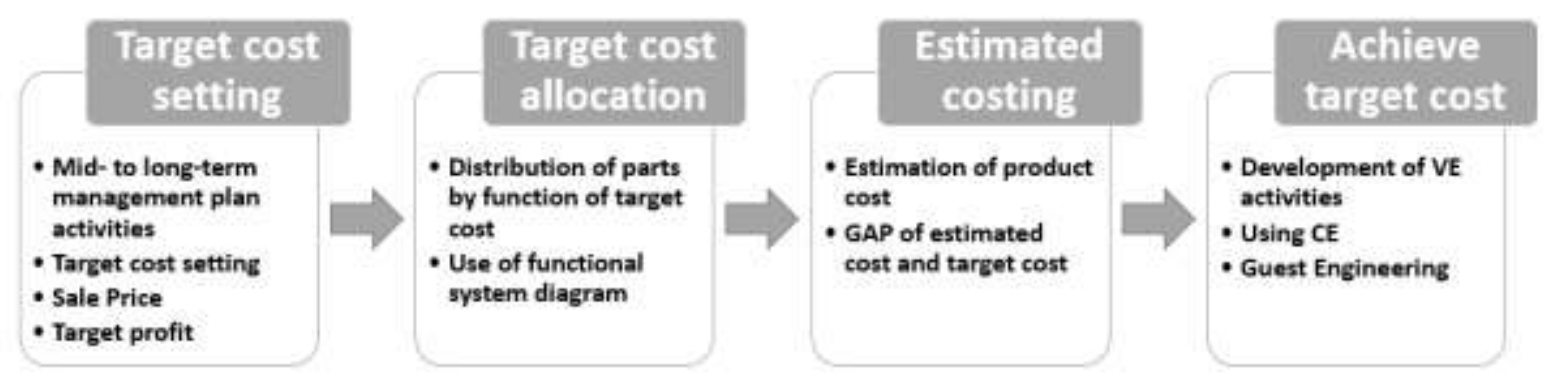

Figure 5 Target cost achievement process

\subsubsection{Activity Stage}

In the activity stage, a TCR operating organization is formed, and enterprise-wide cost reduction activities are performed systematically. In this step, first, TCR goals are set, and KPIs are set for each business department to achieve the goals, and TCR activities (Target Cost, Total Cost Reduction) are conducted, the results are checked, and continuous improvement is performed. Here, the TCR goal setting is when the CEO's cost reduction policy is presented, each business manager reviews the previous year's TCR performance and sets this year's TCR target to $5 \%$ of sales. Table 2 shows the improvement details and improvement activities for each TCR TFT.

Table2 Improvement details and activities for each TCR \& TFT

\begin{tabular}{|c|c|c|}
\hline TFT & Improvement history & Improvement activities \\
\hline $\begin{array}{l}\text { Raw and } \\
\text { subsidiary } \\
\text { materials }\end{array}$ & $\begin{array}{l}\text { Unit price cut } \\
\text { Substitute raw material } \\
\text { Yield reduction } \\
\text { Reduction of manufacturing } \\
\text { defects } \\
\text { Specification improvements }\end{array}$ & $\begin{array}{l}\text { - VE (Value Engineering) activities } \\
\text { - Formulation improvement and alternative raw } \\
\text { materials } \\
\text { - Idea suggestion activity } \\
\text { - Workshop activity } \\
\text { - Raw material and subsidiary material unit price } \\
\text { bidding system } \\
\text { - market research }\end{array}$ \\
\hline Product & $\begin{array}{l}\text { Lot quantity improvement } \\
\text { Specification improvements } \\
\text { raise in unit cost } \\
\text { Quality condition improvement }\end{array}$ & $\begin{array}{l}\text { - Increasing the unit price of items with higher } \\
\text { manufacturing costs } \\
\text { - Sluggish/floating bulk sale } \\
\text { - Charge for sluggish/floating failure costs } \\
\text { - Improvement of cost loss items }\end{array}$ \\
\hline $\begin{array}{l}\text { Labor } \\
\text { expenses } \\
\text { and } \\
\text { expenses }\end{array}$ & $\begin{array}{l}\text { Cost reduction } \\
\text { Increased productivity } \\
\text { Reduction of defects } \\
\text { Reduced rework and improved } \\
\text { yield }\end{array}$ & $\begin{array}{l}\text { - Immediate implementation improvement } \\
\text { activities } \\
\text {-LOB and EB improvement } \\
\text {-Activities to reduce preparation and replacement } \\
\text { time } \\
\text {-Logistics cost improvement activities } \\
\text {-LCA improvement activities } \\
\text {-Idea suggestion activity } \\
\text { - Group activities } \\
\text { - Benchmarking and workshop activities } \\
\text { - Consulting guidance market research }\end{array}$ \\
\hline
\end{tabular}

\subsubsection{Evaluation Stage}

In the evaluation stage, through monthly, semiannual, and annual performance report meetings against cost reduction targets, all divisions report their performance against the KPI indicator targets, and after verifying the performance by the responsible department, and each TFT is evaluated and gets awards..

\subsubsection{Follow-Up Management Stage}


In the post-management stage, through verification in the evaluation stage, additional workshops are held when the performance of each TFT is not achieved, re-establishing a plan to achieve the TCR goal, and then restarting TCR improvement activities.

\subsection{TCR Activity Results}

The case company conducted TCR activities by utilizing VE, CE, and guest engineering to achieve the target cost after deriving the difference between the estimated cost and the target cost.

As a result, as of Figure 6, as of 2019, the company achieved a cost reduction of 23\%, including $7 \%$ for products, 24\% for raw and subsidiary materials, 28\% for labor expenses, and 15\% for new. As shown in Figure 7, the contribution rate from these TCR activities to operating profit was $37 \%$ in $2017,35 \%$ in 2018 , and $50 \%$ in 2019 , reaching average $41 \%$ over three years.

\begin{tabular}{|c|c|c|c|c|c|c|}
\hline \multirow{2}{*}{\multicolumn{2}{|c|}{ Division }} & \multirow{3}{*}{$\begin{array}{c}2017 \\
\text { Price } \\
443\end{array}$} & \multicolumn{2}{|c|}{2018} & \multicolumn{2}{|c|}{2019} \\
\hline & & & \multirow{2}{*}{$\begin{array}{l}\text { Price } \\
484\end{array}$} & \multirow{2}{*}{$\begin{array}{c}\begin{array}{c}\text { Increase } \\
\text { so } \\
\text { Decreasu }\end{array} \\
9 \% \\
\end{array}$} & \multirow{2}{*}{$\begin{array}{c}\text { Price } \\
531\end{array}$} & \multirow{2}{*}{$\begin{array}{c}\begin{array}{c}\text { Increase } \\
\alpha \\
\text { Decrease }\end{array} \\
7 \% \\
\end{array}$} \\
\hline \multirow{3}{*}{$\begin{array}{l}\text { Enterpri } \\
\text { se-wide } \\
\text { cost } \\
\text { savings }\end{array}$} & Products & & & & & \\
\hline & $\begin{array}{l}\text { Rew and } \\
\text { whssidiary } \\
\text { materias }\end{array}$ & 1,262 & 1,476 & $17 \%$ & 1,824 & $24 \%$ \\
\hline & $\begin{array}{l}\text { Labor } \\
\text { expenser }\end{array}$ & 874 & 1,143 & $31 \%$ & 1,465 & $28 \%$ \\
\hline $\begin{array}{c}\text { Target } \\
\text { Cost }\end{array}$ & $\begin{array}{l}\text { New } \\
\text { product }\end{array}$ & 204 & 216 & $6 \%$ & 248 & $15 \%$ \\
\hline \multicolumn{2}{|c|}{ TCR totals } & 2,783 & 3,318 & $19 \%$ & 4,068 & $23 \%$ \\
\hline
\end{tabular}

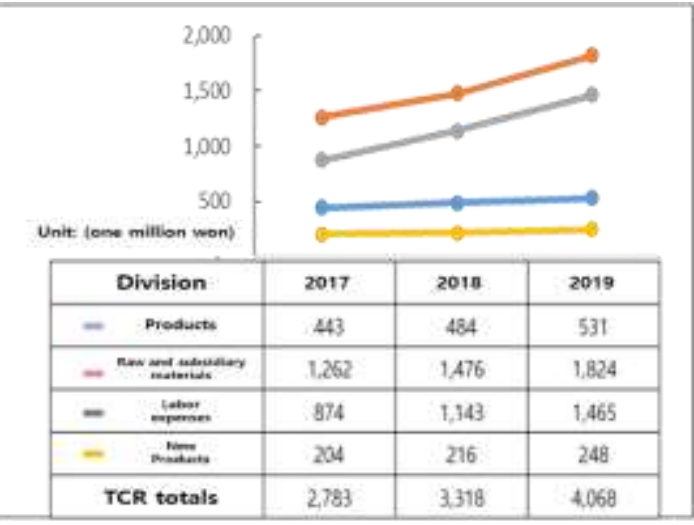

Figure 6 Company C's TCR Performance in 2017-2019

\begin{tabular}{|c|c|c|c|c|c|c|c|c|c|}
\hline & & & & & $t$ cone $m$ & mon) & & & \\
\hline \multirow{2}{*}{ Division } & \multirow{2}{*}{$\begin{array}{l}2017 \\
\text { Price }\end{array}$} & \multicolumn{2}{|c|}{2018} & \multicolumn{2}{|c|}{2019} & \multirow[t]{2}{*}{$60 \%$} & & & \\
\hline & & Price & $\begin{array}{l}\text { Imereme } \\
\text { Decrease }\end{array}$ & Price & $\begin{array}{l}\text { Inergave } \\
\text { Decreaser }\end{array}$ & & & & \\
\hline TCR totals & 2,783 & 3,318 & $19 \%$ & 4,068 & $23 \%$ & 40 & & & \\
\hline $\begin{array}{c}\text { Operating } \\
\text { profit }\end{array}$ & 7,584 & 9,362 & $31 \%$ & 8,115 & $-13 \%$ & \multirow{2}{*}{200} & & & \\
\hline Contributi & & & & & & & 2017 & 2010 & 2019 \\
\hline $\begin{array}{c}\text { On rate of } \\
\text { Operating } \\
\text { profit }\end{array}$ & $37 \%$ & $35 \%$ & $-9 \%$ & $50 \%$ & $41 \%$ & 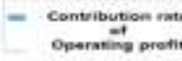 & $3 \pi$ & $35 \%$ & $50 \mathrm{~K}$ \\
\hline
\end{tabular}

Figure 7 Company C's TCR performance in 2017-2019 (operating profit contribution rate)

\section{Conclusions}

As a result of aggregating the performance of Company C's TCR activities in 2019 in terms of raw and subsidiary materials, products, and labor expenses, the reduction of raw and subsidiary materials costs was KRW 1,824 million, with the highest management performance contribution rate (33\%). Next, labor costs were reduced by KRW 1,465 million (contribution rate 31\%), and products were reduced by KRW 921 million (contribution rate 21\%). This result is equivalent to 48\% (4,210 million won) of the 2019 operating profit (84 million won).

Therefore, the results of this study are expected to serve as a good benchmark for the introduction of cost reduction systems and activities of not only domestic and foreign industries but also other industries.

\section{References}

[1] Ji JS, Park SY, Lee DH. Promotion and performance of quality management activities in a small and medium cosmetic manufacturing company: A case study. Journal of The Asian International Journal of Life Sciences. 2019; 18(1): 243-253. 
[2] Yoo SO. The effect of total quality management on the choice of management accounting system. Journal of Industrial Economics and Business. 2005; 18(1): 409-433.

[3] Ahire SL, Golhar DY, Waller MA. Development and Validation of TQM Implementation Constructs. A Journal of the Decision Sciences Institute. 1996; 27(1): 23-56.

[4] Kim DK. Effects of Total Quality Management Activities on Corporate's Innovation Capability and Performance: Focused on the Domestic Foundry Industry [dissertation]. [Daegu (Korea)]: Yeungnam University; 2014.

[5] Park HK. An Empirical Study of the Effects of the Management Quality on Management Performance [dissertation]. [Incheon (Korea)]: Incheon University; 2011.

[6] Lim SR. An Empirical Study on the Influence Factors of the Quality Management Implementation and Performance [dissertation]. [Daejeon (Korea)]: Paichai University; 2014.

[7] Oh JW. A Study on the Effects of Innovation Competency and Management Quality Activities on Business Performance: Based on Malcolm Baldrige Model [dissertation]. [Chungju (Korea)]: Korea National University of Transportation; 2015.

[8] Han SH. Effect of Quality Management on the Performance: Focusing Manufacturing Companies Awarding Korean National Quality Awards [dissertation]. [Chuncheon (Korea)]: Kangwon National University; 2014.

[9] Park MH. Effects of ISO 9001:2008 Requirement Execution and TQM on Financial Performance. Journal of Society Korea Industrial and Systems Engineering. 2012 June; 35(2):80-87.

[10] Yoon JE, Kim YB. A Study on the Effects of Single PPM on Management Performance in Small-Medium Manufacturing Industry. Journal of the Korea Safety Management \& Science, 2012; 14(4): 291-301.

[11] Hamide Özyürek, Metin Yılmaz. Application of Costing System in the Small and Medium Sized Enterprises (SME) in Turkey. International Journal of Economics and Management Engineering. 2015; 9(1): 389-397.

[12] Kim JO. Development and application of P-VE model for cost reduction in steel industry [dissertation]. [Seoul(Korea)]: Myongji University; 2018. 